\title{
RETOFITTING OF REINFORCED CONCRET BWAMS USING CFRP FLEXURAL AND SHEAR
}

\author{
Tariq M. Nahhas, Ph.D. \\ Associate professor of civil engineering \\ Umm AlQura University \\ College of Engineering and Islamic Architecture \\ Makkah, Saudi Arabia
}

\begin{abstract}
In this paper, thirty three tests were conducted on 200x400x3250 mm full-scale reinforced concrete beams retrofitted in flexural and shear using Carbon Fiber-Reinforced Polymer (CFRP) laminates. All beams were tested under four-point bending. The main variables considered were the position and the length of retrofitting of CFRP laminates, six different lengths 500,1000,1500,2000, 2500, and 3000mm were used to retrofit the beams in flexural, while three different position of CFRP, diagonal, vertical and full CFRP strips were applied on the lateral faces of the beams to retrofit the beams in shear. The experimental results, indicated that generally, CFRP laminates help in improving the structure performance by reducing deflections and/or cracking and increasing ultimate strength. The beams retrofitted in shear and flexure by using CFRP laminates are restored to stiffness and strength values nearly equal to or greater than those of the control beams. It was found that the efficiency of the strengthening technique by CFRP in flexure varied depending on the length of CFRP laminates. Also the experimental outcomes prove that CFRP strips distribution can improve the load carrying capacity of the beams retrofitted in shear. The failure modes are controlled by the pre-repair damage flexural crack wherein it causes the CFRP deboning.

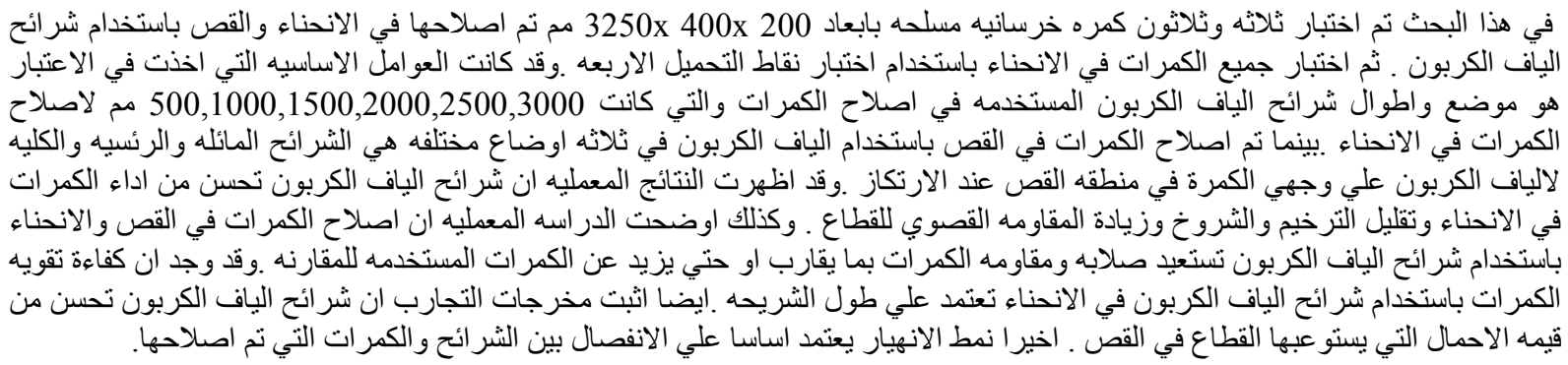

Keywords: Beams, Carbon Fiber Reinforced Polymer (CFRP), Retrofitting, Laminate, Reinforced Concrete beam, Flexure, Shear, Deflections, Ultimate strength.

\section{Introduction}

The Strengthening and rehabilitation of structures are major issues worldwide. In most situations, strengthening is required when there is an increase in the applied load, Human errors in the initial construction, a legal requirement to comply with updated versions of existing codes, or as a result of the loss of strength due to deterioration over time. Different types of strengthening materials are available in the market. Examples of these are Ferro cement, steel plates and fiber reinforced polymer (FRP) laminate. Retrofitting of reinforced concrete (RC) structures by bonding external steel and FRP plates or sheets is an effective method for improving structural performance under both service and ultimate load conditions. It is both environmentally and economically preferable to repair or strengthen structures rather than to replace them totally. With the development of structurally effective adhesives, there have been marked increases in strengthening using steel plates and FRP laminates [1]. FRP has become increasingly attractive compared to steel plates due to its advantageous low weight, high stiffness and strength to weight ratio, corrosion resistance, lower maintenance costs and faster installation time. Earlier research has demonstrated that the addition of carbon fiber reinforced polymer (CFRP) laminate to reinforced concrete beams can increase stiffness and maximum load of the beams. Previous studies have been conducted [2-6] in an attempt to quantify the flexural and shear strengthening enhancements offered by the externally bonded reinforcement (EBR) or near surface mounted (NSM) CFRP laminates. The results of flexural 
tests on RC beams strengthened with both NSM and EBR techniques are discussed in these papers to show that the debonding phenomena for NSM strip strengthened beams are less significant than for EBR plate beams. Moreover, the effect of the loading pattern is analyzed to evaluate the sensitivity of failure modes and loads to different distributions of bending moment and shear along the beam. Finally, the experimental results are compared with the predictions of theoretical models and code provisions. All studies showed that an externally bonded composite, or near surface mounted of CFRP materials, improved the moment capacity of deteriorated concrete beams. In spite of many studies of the behavior of retrofitted beams, the effect of the length of CFRP on the behavior of pre-cracked beams retrofitted by CFRP in flexure and the behavior of retrofitted beams in shear after preloading have not been explored [7-9].

The flexural strength and stiffness of the strengthened beams increased compared to the control specimens. From the results of these studies, it is concluded that the design guidelines of ACI 440.2R-02 and ISIS Canada overestimate the effect of CFRP sheets in increasing the flexural strength of beams with small $\dot{\rho}$ values compared to the maximum value, $\dot{\rho}$ max, specified in these two guidelines. With the increase in the $\dot{\rho}$ value in beams, the ratios of test load to the load calculated using ACI 440 and ISIS Canada increased. Therefore, the equations proposed by the two design guidelines are more appropriate for beams with large $\dot{\rho}$ values. In the strengthened specimens with the large reinforcing bar ratio, close to the maximum code value of $\dot{\rho}$ max, failure occurred with adequate ductility $[10,11]$. Also an experimental results were obtained on two beams: a corroded beam that had been exposed to natural corrosion for 25 years and a control beam, repaired in bending only. Each beam was repaired with one 6-mm-diameter NSM CFRP rod. The beams were tested in a three-point bending test up to failure. Overall stiffness and crack maps were studied before and after the repair. Ultimate capacity, ductility and failure mode were also reviewed. Finally some comparisons were made between repaired and non-repaired beams in order to assess the effectiveness of the NSM technique. The experimental results showed that the NSM technique improved the overall characteristics (ultimate load capacity and stiffness) of the control and corroded beams and allowed sufficient ductility to be restored to the repaired corroded elements, thus restoring the safety margin, despite the nonclassical mode of failure that occurred in the corroded beam, with the separation of the concrete cover due to corrosion products [12].

An experimental work [16] shows that an outcomes proved that CFRP strips distribution can improve the load carrying capacity of the retrofitted beams, provided that the diagonal strips are long enough and that the longitudinal reinforcement is arranged along the whole beam.

This study examined experimentally the flexural and the shear behaviors of RC-beams retrofitted with CFRP laminates. To accomplish this, laboratory testing was conducted on full-size beams. The main variables in this study are the CFRP positions and lengths of CFRP laminates for shear and flexural respectively.

\section{Experimental program}

The experimental work undertaken in this study consisted of four point bending tests of 33 simply supported full scale RC beams after three months of casting them. The beams were divided into two groups. The first one was named BRB, and was focus on flexural behavior of retrofit beams with CFRP in bending, while the second group was named SRB, and was focus on shear behavior of retrofit beams in shear. For group BRB, three beams were used as control beams. The other eighteen were preloaded until flexural cracks appeared and then retrofitted with CFRP laminates with different lengths. Six lengths of CFRP laminates $(500,1000,1500,2000,2500$ and $3000 \mathrm{~mm}$ ) were used, with three nominally equal beams for each length. Finally, the retrofitted beams were loaded until failure and the results were compared with the control beams. For group SRB, three beams were used as control beams, and the other nine were preloaded until shear cracks appeared and then retrofitted with different position technique (diagonal, vertical and full) and finally tested to failure. Figure 1 explain the experimental program and CFRP application for flexural and shear groups.

\subsection{Materials}

A normal strength concrete mix was prepared using Ordinary Portland cement (Type I). The aggregate used consisted of Gravel and sand. The gradation of coarse and fine particles meet the ASTM specification (C136). The maximum aggregate size of gravel was $14 \mathrm{~mm}$ and the free water cement ratio was 0.45 . The concrete mix was designed according to ACI method 211, to have slump 80$100 \mathrm{~mm}$ and 28 days cylinder compressive strength of $35 \mathrm{MPa}$. The average of three concrete compressive strength cylinders was $36.1 \mathrm{MPa}$. The concrete mix is shown in Table 1.

Table1: Mix proportions of concrete, $\mathrm{kg} / \mathrm{m}^{3}$.

\begin{tabular}{|l|l|}
\hline \multicolumn{1}{|c|}{ Material } & \multicolumn{1}{c|}{$\mathrm{kg} / \mathrm{m}^{3}$} \\
\hline Cement & 350 \\
\hline Water & 157.5 \\
\hline Gravel $(5-14 \mathrm{~mm})$ & 1112 \\
\hline sand & 653 \\
\hline
\end{tabular}


The steel bars used for longitudinal reinforcement were tested in static tension in the lab. The elastic modulus was about 211 GPA. The stirrups were manufactured using plain steel bars with nominal diameter 8, while the upper and lower reinforcement steel bars were of 10, 12, and $16 \mathrm{~mm}$ diameter. The mechanical properties for the reinforcing steel used are given in Table 2.

Table 2: Mechanical properties of steel bars.

\begin{tabular}{|c|c|c|c|}
\hline $\begin{array}{c}\text { Diameter } \\
(\mathrm{mm})\end{array}$ & $\begin{array}{c}\text { Elastic } \\
\text { modulus } \\
(\mathrm{GPa})\end{array}$ & $\begin{array}{c}\text { Yield } \\
\text { Stress } \\
(\mathrm{MPa})\end{array}$ & $\begin{array}{c}\text { Ultimate } \\
\text { stress } \\
(\mathrm{MPa})\end{array}$ \\
\hline 8 & 210 & 250 & 370 \\
10 & 211 & 420 & 610 \\
12 & 210 & 415 & 615 \\
16 & 210 & 420 & 630 \\
\hline
\end{tabular}

The CFRP used in this study was laminate of a thickness of $1.4 \mathrm{~mm}$, a width of $60 \mathrm{~mm}$ and the elastic modulus 180 GPA according to the manufacturer. The material used for the bonding of CFRP laminates to the concrete was an epoxy adhesive with compressive strength equal to 50 $\mathrm{MPa}$ according to the manufacturer and it was applied with a total thickness equal to $1.5 \mathrm{~mm}$.

\subsection{Manufacture of beams}

The beams had a rectangular cross-section of 200 $\mathrm{mm}$ width, $400 \mathrm{~mm}$ height, and was $3250 \mathrm{~mm}$ long. The beams of BRB group were designed to have insufficient flexural strength to obtain a pure flexural failure. They had tension reinforcement $(2$ $\phi 12)$, compression reinforcement $(2 \phi 10)$ and the steel bars were tied together with $8 \mathrm{~mm}$ stirrups spacing $100 \mathrm{~mm}$ along the beam, as explained in Figure 2a. The beams in group SBR had the same dimensions, but were cast with a reduced shear reinforcement ratio and a larger longitudinal reinforcement ratio in order to obtain pure diagonal shear cracks without development of flexural cracks. The beams had tension reinforcement ( $3 \phi$ 16), compression reinforcement $(2 \phi 10)$ and were tied with $8 \mathrm{~mm}$ stirrups spacing $400 \mathrm{~mm}$ along the beam as shown in Figure 2b. In all the beams, the clear concrete cover to the main flexural reinforcement was set to $25 \mathrm{~mm}$. This cover was expected to avoid splitting bond failure. Geometry and reinforcement are shown in Figure 2 a\&b. The beams cured by water burlap for one month before the testing date.

\subsection{Testing of control beams}

Four point load bending test was used in this study. This load case was chosen because it gives constant maximum moment and zero shear in the section between the loads, and constant maximum shear force between support and load. The moment was linearly varying between supports and load. The span between the supports was $3000 \mathrm{~mm}$ and the load was applied at points dividing the length into three equal parts as shown in Figure 3. Steel plates were used under the loads to distribute the load over the width of the beam. The testing equipment was a testing machine of $3000 \mathrm{KN}$ capacity.

A linearly variable differential transducer, LVDT, was used to measure the deflection at mid-span, as shown in Figure 3\&4. Deflections and load were recorded during the test. The first crack appeared in the control beams of group BRB at $\mathrm{P}=93 \mathrm{kN}$ and flexural cracks had formed along the beam at $\mathrm{P}=$ $122 \mathrm{kn}$. For the beams in group SRB, shear cracks were initiated in both shear spans. The first shear crack was the critical crack in the beam and it started to develop at $\mathrm{P}=154 \mathrm{kN}$. The load in this group is higher than for those in group BRB due to intensive flexural reinforcement. 


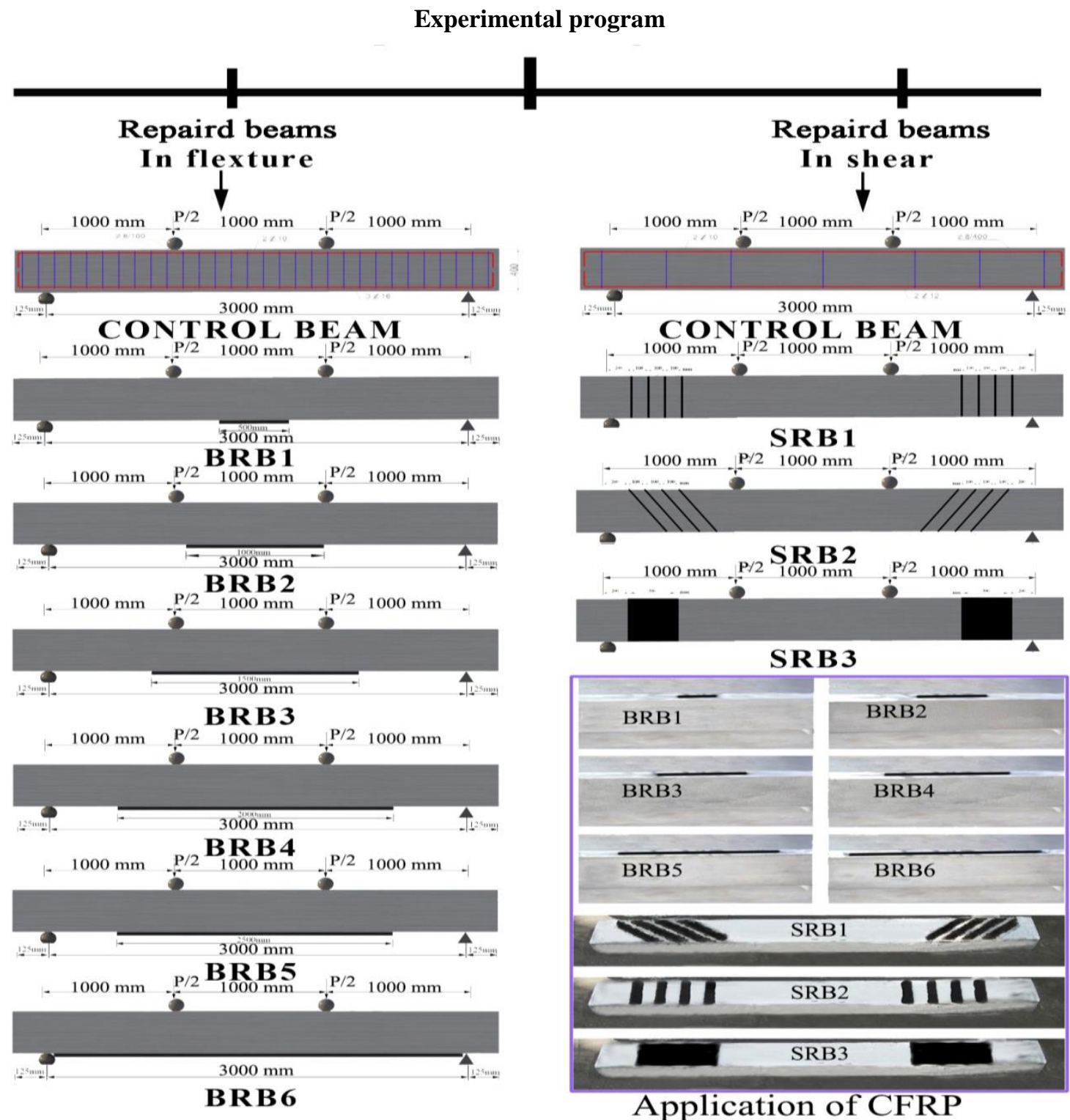

Figure 1: Experimental program for flexural group (BRB) and Shear group (SRB), and applications of CFRP laminate in test series.
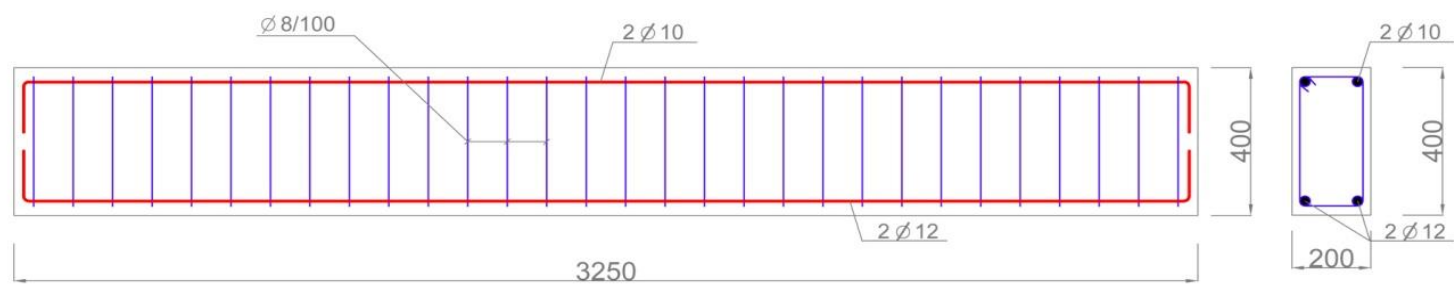

(a) Bending group (BRB)
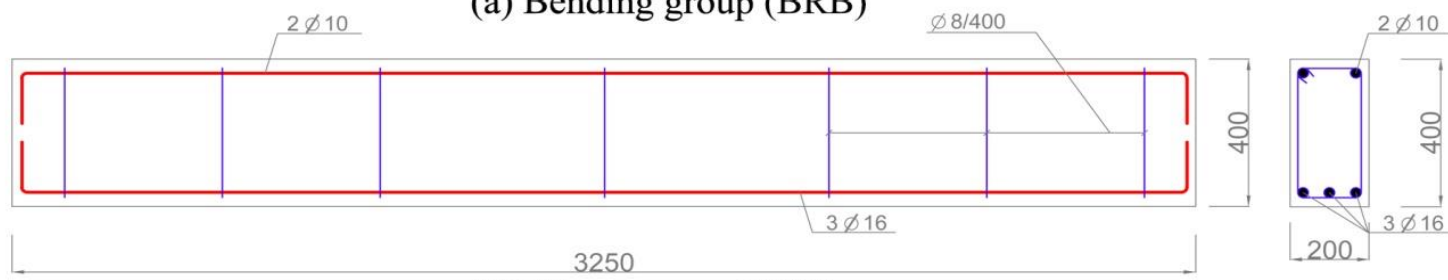

(B) Shear group (BRB)

Figure 2 a, b: Dimensions and reinforcements of RC beams in groups BRB and SRB. 


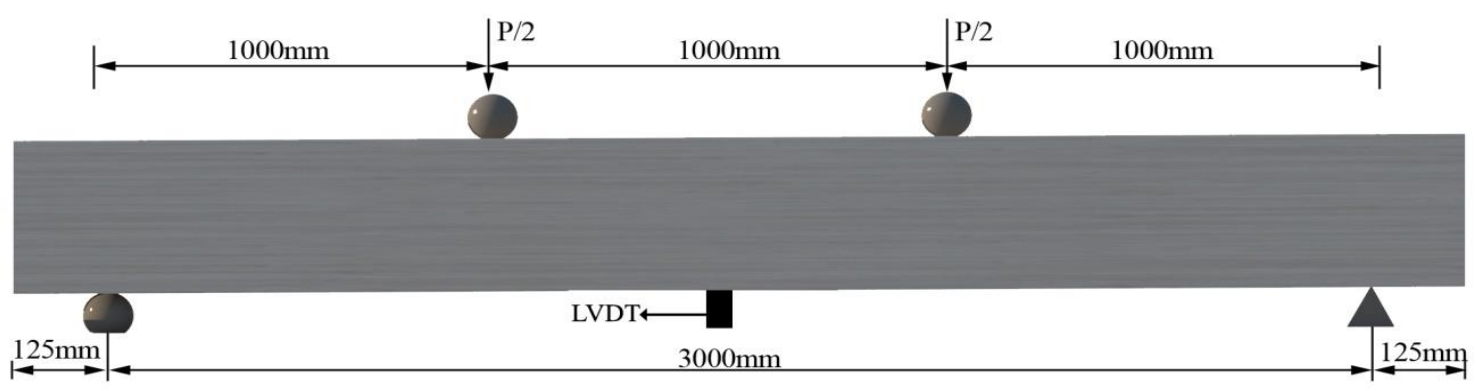

Figure 3: Bending beam Test and position of LVDT.

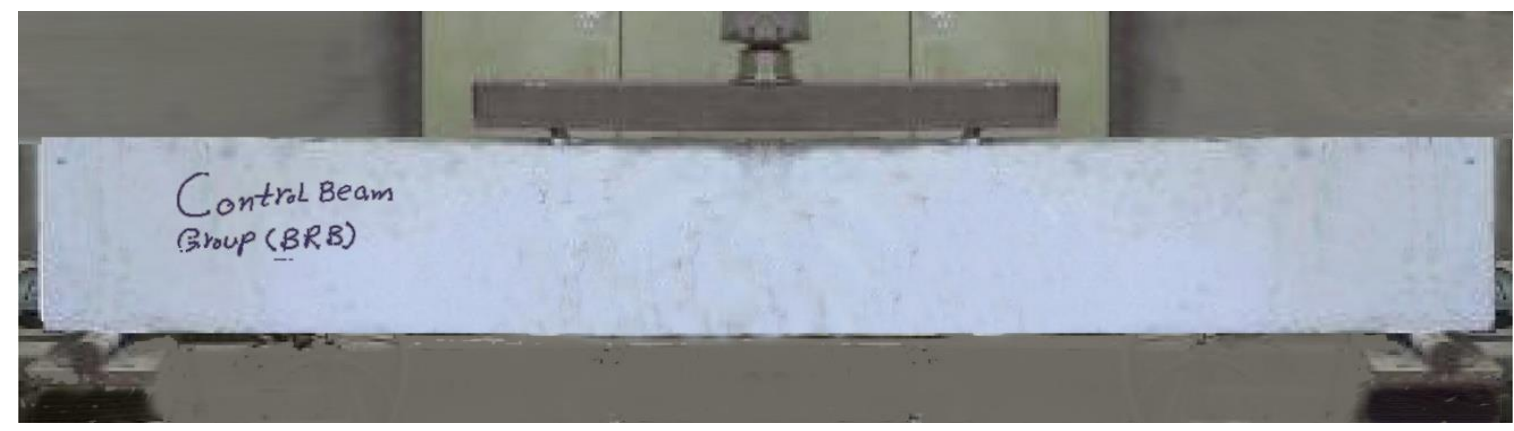

Figure 4: Photo explain the test setup

\subsection{Preloading of beams}

In order to simulate damage, the beams were preloaded before retrofitting. The preloading was done with the same setup as described in Section 2.3. First, the beams were loaded until cracks appeared; the load was $122 \mathrm{kN}$ for beams in group BRB and for beams in group SRB the first shear crack initiated at a load of $154 \mathrm{kN}$, as determined in the control beams test. Then the load was released.

\subsection{Retrofitting of beams}

The beams in group BRB were removed from the test machine and turned over to retrofit them with CFRP as shown in Figure 1. The soffit of the beam was retrofitted with CFRP laminates $60 \mathrm{~mm}$ wide and of six different lengths, $500 \mathrm{~mm}$ (series BRB1), $1000 \mathrm{~mm}$ (series BRB2), $1500 \mathrm{~mm}$ (series BRB3), $2000 \mathrm{~mm}$ (series BRB4), $2500 \mathrm{~mm}$ (series BRB5), and $3000 \mathrm{~mm}$ (series BRB5) as shown in Figure 1. In order to ensure correct application of the external strengthening materials, it was considered necessary to improve the concrete surface characteristics on the contact areas to be bonded. Special consideration was given to surface preparation before applying the epoxy adhesive. Uniform mechanical grinding was used to roughen the surface of the concrete substrate and remove the surface grease and smoothness. The free particles and dust on the beams' concrete surfaces were vacuum-cleaned with compressed air after grinding. After that the epoxy adhesive was applied to both the CFRP laminate and the concrete surface. Finally the laminates were applied with a constant pressure with rollers to ensure complete bond between the concrete and the CFRP laminates and avoid any entrapped air bubbles at the epoxy/concrete or epoxy/ sheet interface. The laminate was positioned at the center of the beam width as shown in Figure 1 (application of CFRP). It must be noted that the laminates were applied when the beams were subjected to a negative moments corresponding to their own dead weight. This implies a small prestressing effect which could be obtained by a jack in the case of on-site repair. For the beams in group SRB, the web of the beam was retrofitted with CFRP laminates $60 \mathrm{~mm}$ wide and $400 \mathrm{~mm}$ long on the two faces of beams in vertical and full positions, while the length is more $500 \mathrm{~mm}$ for diagonal position as shown in Figure 1(application of CFRP). The same procedure was used as for the beams in group BRB, but the position of the laminate was different.

\subsection{Testing of retrofitted beams}

The beam specimens were allowed to cure under laboratory conditions for at least 2 weeks prior to testing, then the beams were retested under four point bending until failure occurred. The tests were performed using the same setup as described in Section 2.3. At the end of each load increment, deflection, ultimate load, type of failure etc., were carefully observed and recorded. The experimental set-up and the beams with GFRP strips are shown in Figure. 3\&4, respectively. 


\section{Results and discussions}

\subsection{Beams in flexure group (BRB)}

\subsubsection{Control beams}

The load versus mid-span deflection curves for the three control beams are shown in Figure. 5. The beams behave in a ductile manner and gives large deflection before the final failure. This is the typical behavior of an under-reinforced RC member [14]. The difference between the three specimens is rather small, and the mean value, also indicated in the figure, will be used. The curve includes a linear response up to the load $45 \mathrm{KN}$. The appearance of a crack was first noted at load $93 \mathrm{KN}$. The mid-span deflection curve illustrates the nonlinearities at cracking of the concrete. After about $120 \mathrm{KN}$ load flexural cracks formed and widened as loading increased. The maximum load was $148 \mathrm{KN}$ as shown in the figure. After maximum load, the cracks did not grow in length for the remainder of the test but the flexural cracks in the constant moment region widened. The failure of a control beam is shown in Figure 5.

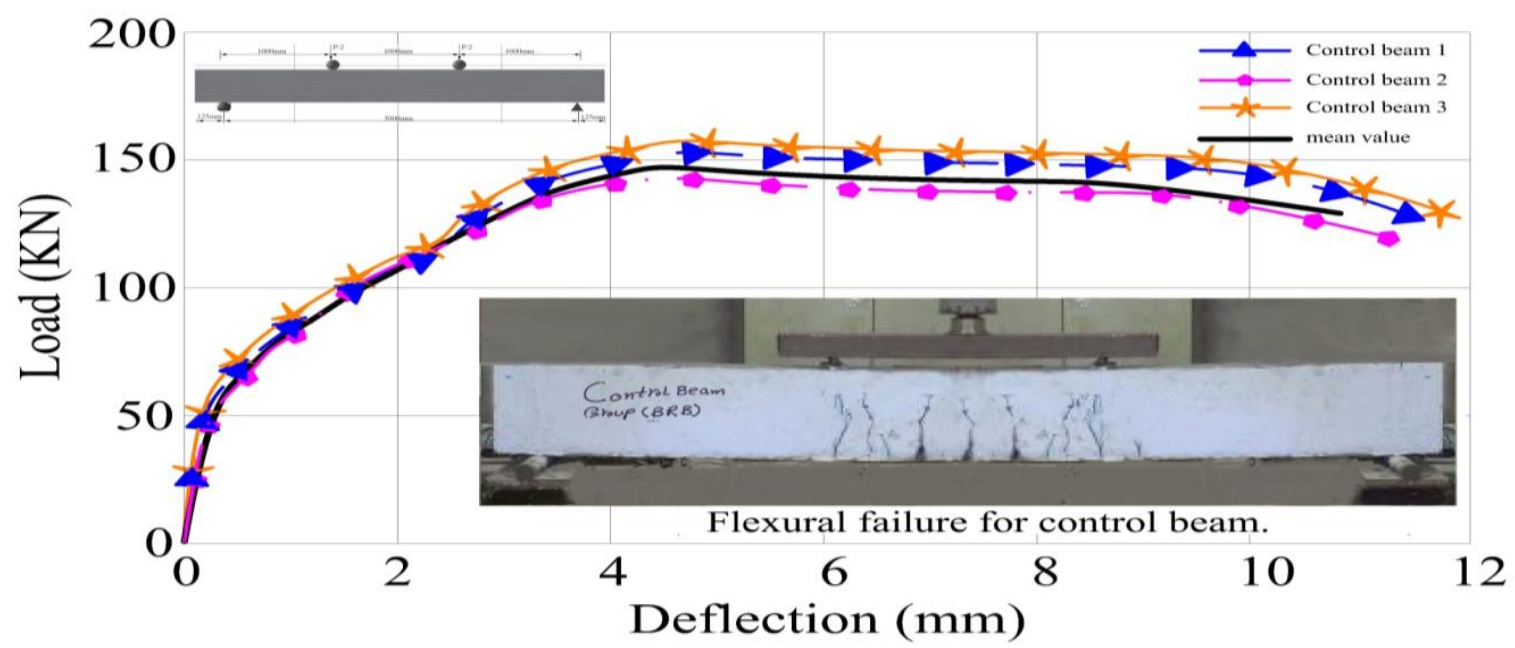

Figure 5: Load deflection and flexural failure for control beam

\subsubsection{Retrofitted beams:}

The load-deflection curves for the individual beams in series BRB1, BRB2, BRB3, BRB4, BRB5 and BRB6 are shown in Figure 6. The results from the three nominally equal beams in each series are close, which indicates that the retrofitting was performed in a well-defined manner. The mean curve will be used in the following. The mean load-deflection curves for the retrofitted beams and for the control beams are shown in Figure 7a. As shown in the figure the stiffness of all beams at small load is almost the same. From a load around $100 \mathrm{KN}$-cracking stage- the stiffness of the control beam decreases notably due to cracking. The decrease in stiffness is smaller for the retrofitted beams since the CFRP prevents cracks to develop and widen. The longer the CFRP the stiffer the beam. This is probably because the longer CFRP strips have a full anchorage length outside the maximum moment region and are hence more efficient in the cracking zone. Some contribution to the stiffness may also be due to the stiffening of the beam caused by the CFRP outside the cracking region. It should be noted that if a control beam would be loaded until cracking, unloaded, and then subjected to load again, the stiffness would be somewhat lower the second time due to the damage in the beam. This means that even if the curve of series BRB1, and BRB2 is similar to that of the control beam the CFRP has improved the beam and restored the stiffness to the level of the control beam. The curves reveal that the strengthening process has significantly increased the maximum load in as CFRP length increase. The maximum loads in series BRB1,BRB2,BRB3,BRB4,BRB5, and BRB6 that represent different lengths of CFRP were $156,183,211,228,236$, and $240 \mathrm{kN}$, which is a more than $5 \%, 23 \%, 42 \%, 54 \%, 59 \%$, and $62 \%$ increase compared to the control beam respectively as shown in Figure $7 \mathrm{~b}$. 

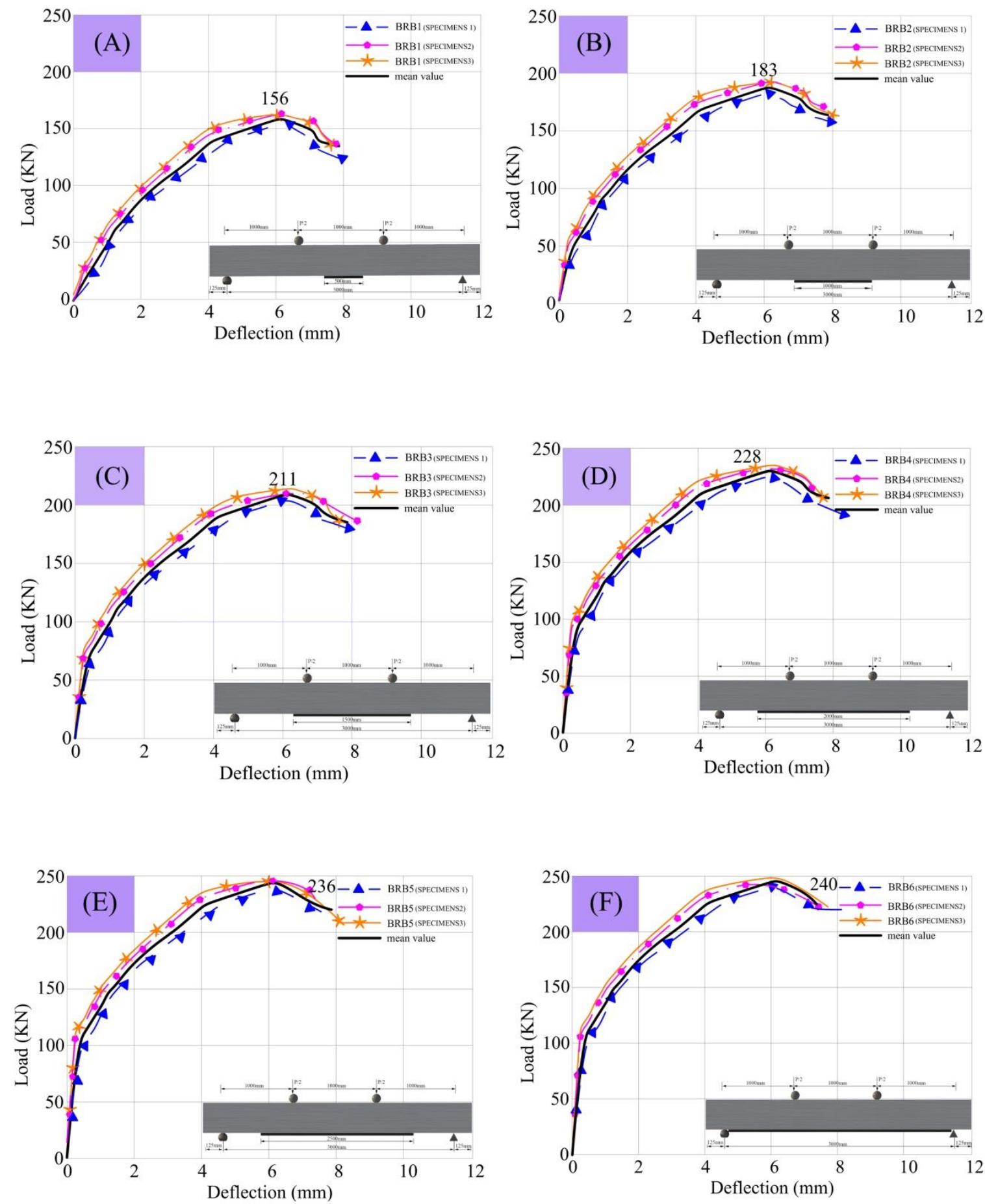

Figure 6: Comparison between load-deflection curves for individual retrofitted beams in group BRB. (BRB1, $\mathrm{BRB} 2, \mathrm{BRB} 3, \mathrm{BRB} 4, \mathrm{BRB} 5$ and BRB6). 
All beams experienced a brittle failure mechanism, however in this case sudden debonding of the CFRP plate from the concrete occurred without

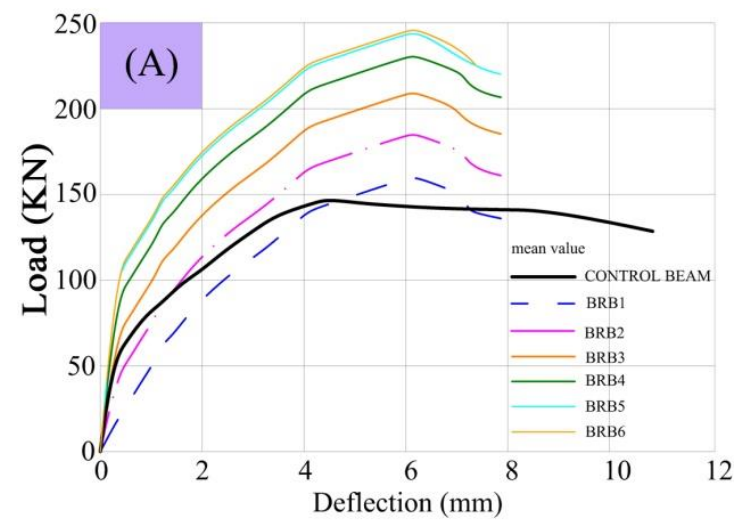

concrete splitting. This failure was due to high shear stress occurring at the ends of the CFRP.

Figure 7: Comparison between mean load-deflection curves for retrofitted beams and control beam in group BRB.

The properties of the adhesive are probably important in relation to the debonding failure. A lower stiffness and higher fracture energy will probably weaken the tendency of debonding. For BRB1, BRB2, and BRB2 deboning occurred earlier than for BRB4, 5, 6. The main reason leading to this is that BRB1, BRB2, and BRB2 do not have a full anchorage length outside the maximum moment region, hence higher shear stress concentration will occur compared to for the longest CFRP, Figure8.
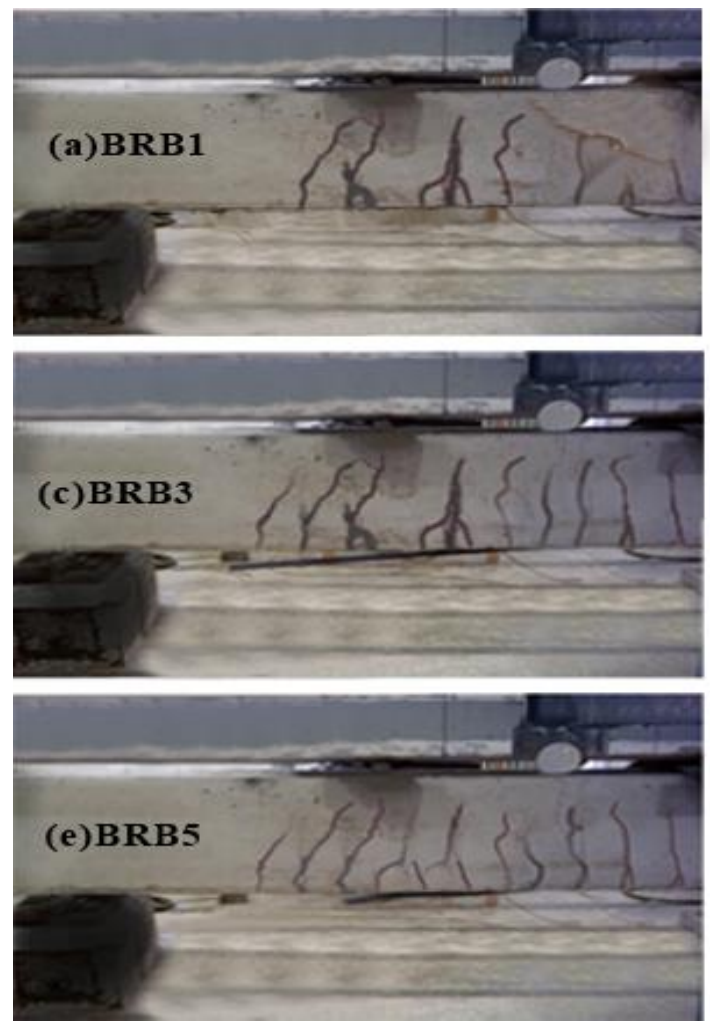
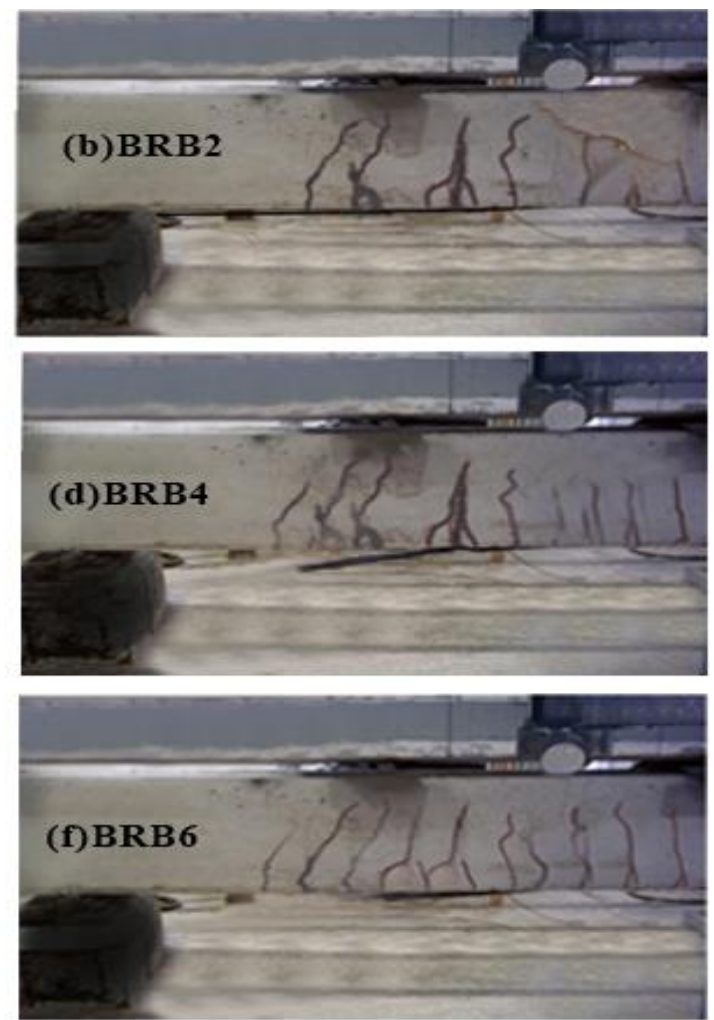

Figure 8: Debonding failures in group BRB. 
The crack propagation and the final crack pattern of the beam are greatly different from that of the control beam. The control beam had few flexural cracks with large width, and the retrofitted beam had many flexural cracks with smaller width. This indicates that the propagation of cracks was confined by the CFRP laminates. In addition, the cracks in series BRB5, BRB6 were fewer and had smaller width than in the other retrofitted beams.

The results indicate that the externally bonded CFRP has increased the stiffness and maximum load of the beam. In addition, the crack width and the deflection have decreased. The efficiency of the strengthening by CFRP in flexure varied depending on the length of the CFRP, see Figure 8.

\subsection{Beams in shear groups $\mathrm{SRB}$ \\ 3.2.1. Control beam}

The load versus mid-span deflection curves for the control beams are shown in Figures 9, 10. It is clear that the beam failed in a brittle manner and has a low energy absorption before failure. This is the typical behavior of an ordinary RC member with insufficient shear steel. The difference between the three specimens is rather small, and the mean value, also indicated in the figure, will be used. The curve has linear response until $80 \mathrm{KN}$. The ultimate load of the control beams was $275 \mathrm{KN}$. The cracking patterns consist of a pure diagonal shear crack in the constant shear spans. This is due to the reduced amount of shear reinforcement.

\subsubsection{Retrofitted beams}
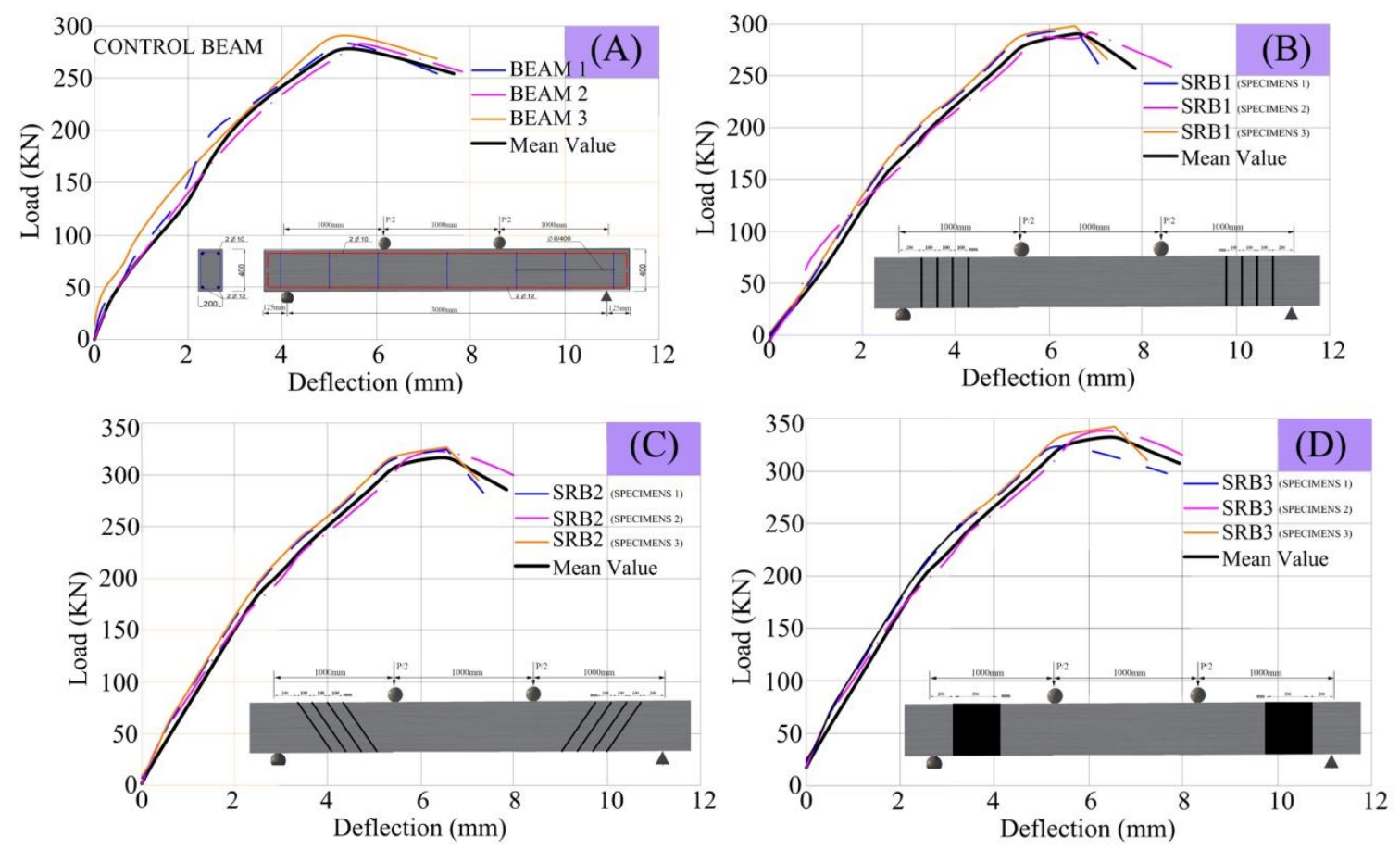

Figure 9: Load-deflection curves for individual retrofitted beams in group SRB

The load versus mid-span deflection curve for the mean value of the retrofitted beams is compared with the response of the control beams in Figure 10a. The performance of an inclined layout of CFRP laminates was evaluated through beams tests SRB2. A CFRP laminate that is perpendicular to inclined cracks is more efficient at resisting shear forces than one that is oriented perpendicular to a member's axis (Beams SRB1). Moreover, more inclined laminates intercept a critical shear crack than vertical strips spaced at the same horizontal spacing. The inclined laminates on SRB2were longer than the vertical laminates on SRB1, which compensated for the difference in width to produce equal CFRP surface areas [15].

The control beam shows more softening due to crack propagation, while in the retrofitted beam, the cracks are arrested by the CFRP, and this makes the curve of the retrofitted beam somewhat straighter than the control beam curve. The maximum load of the strengthened beam SRB1, SRB2, andvSRB3 were 290, 315, and $325 \mathrm{KN}$ with that that strengthening increases the maximum load by over $5 \%, 14 \%$, and $18 \%$, when compared with the control beam respectively as shown in Figure $10 \mathrm{~b}$ 

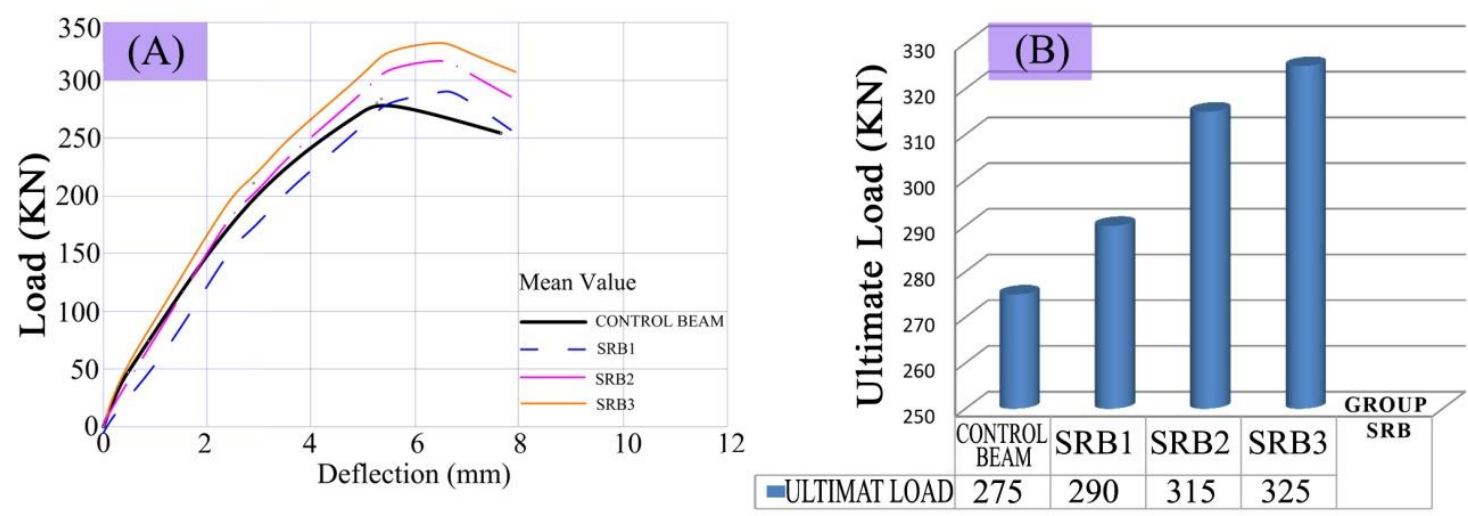

Figure 10: Load-deflection curves for individual retrofitted beams in group SRB

A de-bonding failure occurred for all beams also in this group. The debonding mode is due to cracking of the concrete underneath the
CFRP plate. The beam after failure appears in Figure 11, which clearly shows the shear crack cross the bond area in the concrete.

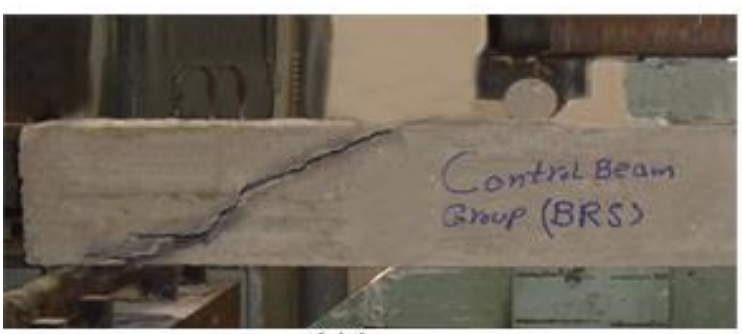

(A)

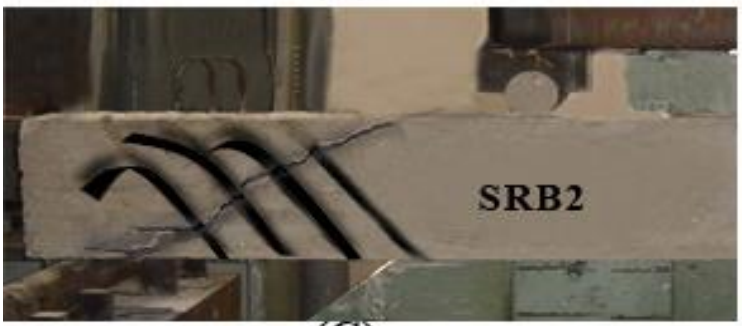

(C)

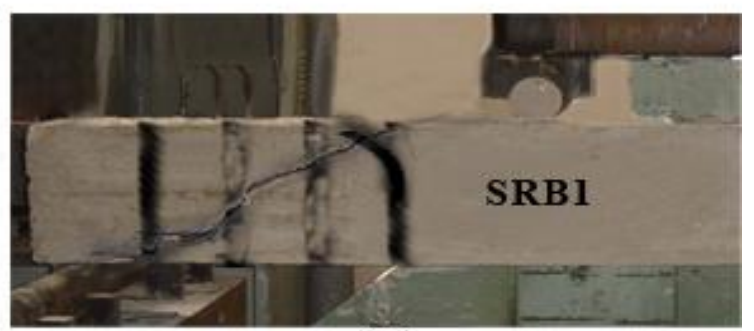

(B)

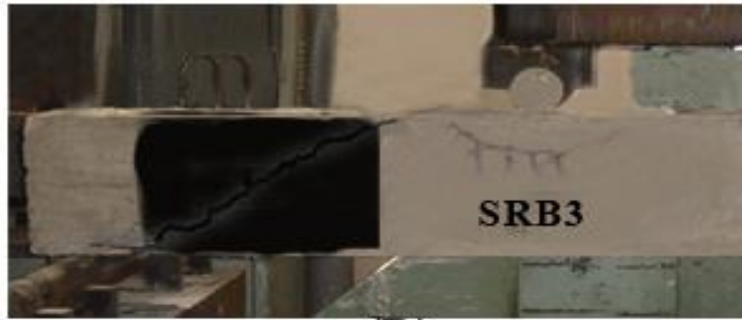

(D)

Figure 11: De-bonding and shear failures in group SRB.

\section{Summery and conclusions}

This paper reported an experimental program investigating the behavior of full scale RC beams retrofit with CFRP laminates in flexural and shear after preloading. The effect of longitudinal (in flexural) CFRP laminates with different lengths and different positions of it (in shear) when externally bonded to the beam's soffit with epoxy adhesives on thirty three full scale RC beams is investigated. The beams were divided into two groups based on the locations of CFRP laminates in flexural or shear. Group one had three control beams and eighteen beams retrofitted with different lengths of CFRP in flexural $(500,1000,1500,2500$, and $3000 \mathrm{~mm}$ ), three beams for each length, and the second group had three control beams and nine retrofit beams with different position (vertical, diagonal, and full) on the two faces of beams. The beams were retested under four points bending until failure occurred. At the end of each load increment, deflection, ultimate load, type of failure etc., were carefully observed and recorded Observations and conclusions from these tests were as follows:

1- The retrofitting schemes have much effect on improving bending stiffness of concrete beams. CFRP sheets have high tensile strength and can improve the ultimate loads and bending stiffness of RC beams.

2- Employing externally bonded CFRP laminates resulted in an increase in maximum load. The increase in maximum load of the retrofitted specimens reached values of about $5-18 \%$ for 
retrofitting in shear and $23 \%$ up to $62 \%$ for retrofitting in flexure depends on the position and length of CFRP laminates respectively. Moreover, retrofitting shifts the mode of failure to be brittle.

3- $\quad \mathrm{RC}$ beams retrofit with CFRP were found to have fine cracks evenly distributed along the span, the crack width observed for the retrofit beams is decreased compared to the control beams.

4- Experimental results showed that increasing the CFRP laminates length in flexural

\section{References}

[1] Aslam, Muhammad, Shafigh, Payam, Jumaat, Mohd Zamin, \& Shah, SNR. (2015). Strengthening of RC beams using prestressed fiber reinforced polymers A review. Construction and Building Materials, 82, 235-256.

[2] Fayyadh, Moatasem M., \& Razak, Hashim Abdul. (2012). Assessment of effectiveness of CFRP repaired RC beams under different damage levels based on flexural stiffness. Construction and Building Materials, 37, 125-134.

[3] Spadea, Giuseppe, Bencardino, Francesco, Sorrenti, Fabio, \& Swamy, Ramnath Narayan. (2015). Structural effectiveness of FRP materials in strengthening RC beams. Engineering Structures, 99, 631-641.

[4] Kalfat, R., Al-Mahaidi, R., \& Smith, S.T. (2013). Anchorage devices used to improve the performance of reinforced concrete beams retrofitted with FRP composites: state-of-the-art review. J Composite Construction, 17, 14-33.

[5] Bilotta, Antonio, Ceroni, Francesca, Nigro, Emidio, \& Pecce, Marisa. (2015). Efficiency of CFRP NSM strips and EBR plates for flexural strengthening of $\mathrm{RC}$ beams and loading pattern influence. Composite Structures, 124, 163-175.

[6] El-Sayed, Ahmed K., (2014). Effect of longitudinal CFRP strengthening on the shear resistance of reinforced concrete beams Composites Part B. Engineering, 58, 422-429.

[7] El-Sayed, Ahmed K., Al-Zaid, Rajeh A., AlNegheimish, Abdulaziz I., Shuraim, Ahmed B., \& Alhozaimy, Abdulrahman M. (2014), Long-term behavior of wide shallow RC beams strengthened with externally bonded CFRP plates. Construction and Building Materials, 51, 473-483.

[8] Rezazadeh, Mohammadali, Costa, Inês, \& Barros, Joaquim. (2014). Influence of prestress level on NSM CFRP laminates for the flexural strengthening of RC beams. Composite Structures, 116, 489-500. retrofitting can make the CFRP more effective for concrete repair and strengthening. This means that insufficient strengthening lengths do not produce the intended strengthening effect.

5- For the same surface area of CFRP laminates, there is a significant strength benefit derived from inclining CFRP strips compared with the normal to a member's axis.

6- The results showed that the main failure mode was plate debonding which reduces the efficiency of retrofitting.

[9] Breveglieri, M., Aprile, A., \& Barros, J.A.O. (2015). Shear strengthening technique using steel and CFRP bars in RC beams of different percentage of existing stirrups. Composite Structures, 126, 101-113.

[10] Verbruggen, Svetlana, Aggelis, Dimitrios G., Tysmans, Tine, \& Wastiels, Jan. (2014). Bending of beams externally reinforced with TRC and CFRP monitored by DIC and AE. Composite Structures, 112, 113-121.

[11] Esfahani, M.R., Kianoush, M.R., \& Tajari, A.R. (2007). Flexural behaviour of reinforced concrete beams strengthened by CFRP sheets. Engineering Structures, 29, 2428-2444

[12] Almassri, Belal, Kreit, Amjad, Al Mahmoud, Firas, \& François, Raoul. (2014). Mechanical behavior of corroded RC beams strengthened by NSM CFRP rods Composites. Part B. Engineering, 64, 97-107.

[13] Bocciarelli, Massimiliano, Feo, Christian di, Nisticò, Nicola, Pisan, Marco Andrea I., \& Poggi, Carlo. (2013). Failure of RC beams strengthened in bending with unconventionally arranged CFRP laminates. Composites Part B: Engineering, 54, 246-254.

[14] Yungon Kim, Wassim M. Ghannoum, James O. Jirsa. Shear behavior of full-scale reinforced concrete T-beams strengthened with CFRP strips and anchors Construction and Building Materials, 94, (2015), 1-9.

[15] Daugevičius, Mykolas, Valivonis, Juozas, Beinaravičius, Artūras, Skuturna, Tomas, \& Budvytis, Marius. (2013). Experimental Investigation of the Load Carrying Capacity of Eccentrically Loaded Reinforced Concrete Elements Strengthened with CFRP. Procedia Engineering 57, 232 - 237.

[16] Heiza Kh, Kandeel M,S Hussain M.(2014) finite element modeling high strength RC slabs, international journal of structure analysis design IJSAD, volume 1 : ISSUE3 [ ISSN:2372-4102]. 